\title{
Differences in obstetric care among nulliparous First Nations and non-First Nations women in British Columbia, Canada
}

\author{
Corinne A. Riddell MSc, Jennifer A. Hutcheon PhD, Leanne S. Dahlgren MD MHSc
}

Competing interests: Corinne Riddell reports funding from the Canadian Institutes of Health

Research during the conduct of the study. No other competing interests were declared.

This article has been peer reviewed.

Accepted: Sept. 15, 2015 Online: Nov. 2, 2015

Correspondence to: Corinne Riddell, corinne .riddell@mail.mcgill.ca

CMAJ 2016. DOI:10.1503/ cmaj.150223

\begin{abstract}
Background: Canada's Aboriginal population faces significantly higher rates of stillbirth and neonatal and postnatal death than those seen in the general population. The objective of this study was to compare indicators of obstetric care quality and use of obstetric interventions between First Nations and non-First Nations mothers in British Columbia, Canada.
\end{abstract}

Methods: We linked obstetrical medical records with the First Nations Client File for all nulliparous women who delivered single infants in British Columbia from 1999 to 2011. Using logistic regression models, we examined differences in the proportion of women who received services aligned with best practice guidelines, as well as the overall use of obstetric interventions among First Nations mothers compared with the general population, controlling for geographic barriers (distance to hospital) and other relevant confounders.

Results: During the study period, 215993 single births occurred in nulliparous women in British
Columbia, 9152 of which were to members of our First Nations cohort. First Nations mothers were less likely to have early ultrasonography (adjusted risk difference $=10.2$ fewer women per 100 deliveries [95\% confidence interval $\{\mathrm{Cl}\}$ -11.3 to -9.3$]$ ), to have at least 4 antenatal care visits (3.6 fewer women per 100 deliveries [95\% $\mathrm{Cl}-4.6$ to -2.6$]$ ), and to undergo labour induction after prolonged ( $>24$ hours) prelabour rupture of membranes $(-5.9[95 \% \mathrm{Cl}-11.8$ to $0.1])$ or at post-dates gestation $(-10.6[95 \% \mathrm{Cl}$ -13.8 to -7.5$]$ ). Obstetric interventions including epidural, labour induction, instrumental delivery and cesarean delivery were used less often in First Nations mothers.

Interpretation: We identified differences in the obstetric care received by First Nations mothers compared with the general population. Such differences warrant further investigation, given increases in perinatal mortality that are consistently shown and that may be a downstream consequence of differences in care.
$\mathrm{A}$ lthough overall rates of stillbirth and infant death have declined in Canada during the last century, Aboriginal people in Canada still have significantly higher rates of stillbirth, as well as neonatal and postneonatal mortality, when compared with the general population. ${ }^{1-3}$

Disparities in stillbirths and neonatal deaths may be related to decreased provision or quality of care by providers, or to lower uptake of care by First Nations mothers compared with women in the general population. ${ }^{2,4}$ Our primary objective was to compare the quality and level of obstetric care between First Nations mothers and mothers in the general population of British Columbia. The chosen indicators reflect standards of care established by national practice guidelines. Our secondary objective was to examine differences in the use of obstetric interventions during labour and delivery, such as induction of labour or cesarean delivery, between these mothers.

\section{Methods}

\section{Setting and design}

We performed a retrospective cohort study involving all first-time mothers who delivered single infants either at home with a registered midwife or in hospital in British Columbia between Apr. 1, 1999, and Mar. 31, 2011. We restricted participants to nulliparous women to focus on comparing the experiences of firsttime mothers, for whom antenatal care and labour experiences should be more comparable. Mode of delivery and pregnancy outcome heavily influence the management of subsequent pregnancies, providing additional support for this focus.

\section{Sources of data}

We linked maternal delivery records from the British Columbia Perinatal Data Registry ${ }^{5}$ to the British Columbia Ministry of Health Discharge 
Abstract Database ${ }^{6}$ using the maternal personal health number to combine information on maternal characteristics and obstetric service outcomes. This registry is a quality-controlled population database containing abstracted medical chart information from more than $99 \%$ of deliveries in the province. A recent validation study showed high validity of many variables in this analysis. ${ }^{7}$ The Discharge Abstract Database has been previously validated for perinatal data. ${ }^{8}$ Using the maternal personal health number, we linked these data to the First Nations Client File, which is a cohort of First Nations people who are found in Aboriginal Affairs and Northern Development Canada's Indian Registry System, and their descendants who may be eligible to register. ${ }^{9}$ The last linkage was to a geographic database that encoded the distance between the centre of the maternal residential postal code and the closest hospital with planned obstetric services, according to highway networks, in kilometres. This database also classified maternal postal code as either urban or rural (Appendix 1, available at www.cmaj.ca/ lookup/suppl/doi:10.1503/cmaj.150223/-/DC1).

The British Columbia Vital Statistics Agency, British Columbia Ministry of Health, Perinatal Services BC, and the Data and Information Planning Committee (which provides stewardship over the First Nations Client File) approved access to and use of the data facilitated by Population Data British Columbia for this study. The study was approved by the University of British Columbia and British Columbia Children's and Women's Hospital research ethics boards. This project follows the Canadian Institutes of Health Research guidelines for research involving Aboriginal people ${ }^{10}$ and is carried out in collaboration with the Maternal/Child Health Group of the First Nations Health Authority.

\section{Outcome measures}

No universally agreed upon indicators of quality obstetric care currently exist. ${ }^{11}$ Because our interest was in exploring differences in care processes, we identified process indicators that are aligned with best practice guidelines set by the Society of Obstetricians and Gynaecologists of Canada and that reflect services provided as part of standard care.

We identified the following indicators of care: group B streptococcus testing and antibiotic use by those women with positive test results among deliveries at or beyond 37 weeks' gestation; ${ }^{12}$ at least 4 primary care antenatal visits in pregnancies in which delivery occurred at or beyond 39 weeks' gestation (although there is no optimal number of visits, the World Health Organization recommends that women have at least 4 visits during preg- nancy) $;{ }^{13}$ ultrasonography before 20 weeks' gestation (the Society of Obstetricians and Gynaecologists of Canada recommends "pregnant women should be offered a routine second trimester ultrasound" and has recently stated that, ideally, all women should be offered first-trimester ultrasonography for pregnancy dating); ${ }^{14,15}$ medical induction of labour among term deliveries in women who have prelabour rupture of membranes (induction of labour is recommended within the first $24 \mathrm{~h}$ after membrane rupture,${ }^{16}$ medical induction of labour in women at or beyond 41 weeks' gestation ("post-dates"), examined overall and within groups of women who did and did not have an early ultrasound; ${ }^{17}$ and planned cesarean delivery performed at or beyond 39 weeks' gestation, for fetuses in breech position. Families often choose to have a planned cesarean delivery and it is advised that planned cesareans should not be scheduled for earlier than the 39th week ${ }^{18}$ (unless clinically indicated) to reduce newborn respiratory distress and other morbidities.

In addition, we investigated the use of the following obstetric interventions: pain management (by nitrous oxide-oxygen mixture or epidural); labour induction by any method; labour augmentation through artificial rupture of membranes or use of oxytocin; instrumental delivery, using vacuum or forceps; and cesarean delivery overall, for the indication of labour dystocia, for the indication of nonreassuring fetal monitoring and elective.

\section{Statistical analyses}

We compared indicators of obstetric care quality in First Nations mothers with those in non-First Nations mothers using logistic regression models before and after adjustment for distance to hospital (coded as $0-50 \mathrm{~km}$ from hospital, 51-100 km, $101-150 \mathrm{~km}, 151-200 \mathrm{~km}$ and $\geq 200 \mathrm{~km})$. As a sensitivity analysis, we adjusted the models for rural residence, rather than distance. We did not adjust indicators of care models for differences in maternal characteristics, because such differences do not justify differences in the quality indicators.

We adjusted obstetrical interventions models for maternal age, prepregnancy body mass index, diabetes (pre-existing or gestational) and hypertension (pre-existing or gestational, International Classification of Diseases 9th and 10th [Canadian version] revision codes 642.0-642.2, 646.1646.6 and O10-O16). We adjusted for continuous covariables - age and body mass index (BMI) - using linear or nonlinear terms as appropriate (Appendix 1). As recommended (Appendix 1), ${ }^{19-21}$ we did not adjust our models for measures of socioeconomic status. Socioeconomic differences are downstream of ethnicity at birth. Adjustment for such factors is a form of over- 
adjustment that conditions on causal intermediates and leads to biased estimates of the total effect. $^{20,21}$

We used multiple imputation to account for missing data regarding distance and body mass index (Appendix 1). We used the user-written "mimrgns" command in Stata version 12 (StataCorp, College Station, TX) to estimate the average marginal risk difference and $95 \%$ confidence interval $(\mathrm{CI})$ for each outcome and combined across imputed datasets using Rubin's rules. ${ }^{22}$
We used QGIS 2.4.0 to map the geographic distribution of First Nations mothers in the province.

\section{Results}

We identified 215993 deliveries of single infants to first-time mothers, of which 9152 (4.2\%) births were to First Nations mothers. First Nations mothers were more likely than non-First Nations mothers to live in the more rural parts of the province (i.e., in the north and northwest, Fig-

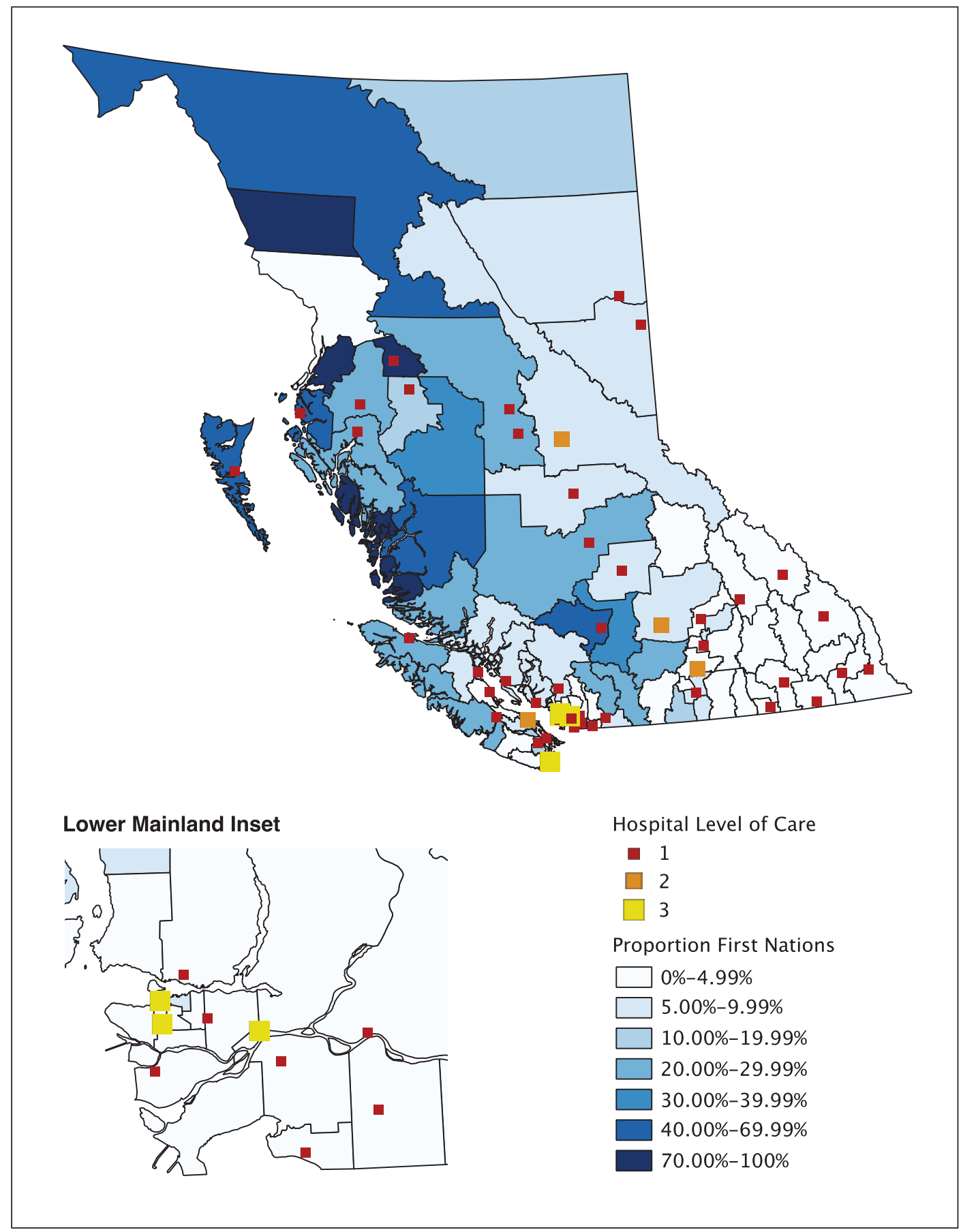

Figure 1: Geographic distribution of First Nations mothers in British Columbia. 
ure 1) and to live farther from their closest hospital (Table 1). First Nations mothers were 7 times as likely as other mothers to have their first child before their 20th birthday (Figure 2). Although the median prepregnancy BMI for First Nations mothers was similar to that for non-First Nations mothers, age-specific distributions showed that First Nations mothers had higher BMIs (Appendix 1). In addition, First Nations mothers were more likely to have a preterm delivery $(<37 \mathrm{wk}$ gestational age) and much less likely to deliver post-dates ( $\geq 41 \mathrm{wk}$ ) than non-First Nations mothers. Gestational diabetes occurred more frequently in non-First Nations mothers, but after accounting for age, the occurrence of gestational diabetes was similar between the two groups (Appendix 1). Rates of gestational hypertension were also similar, with slightly higher agespecific rates among First Nations mothers (Appendix 1).

Rates of group B streptococcus testing were modestly higher in the general population compared with First Nations mothers (Table 2), but this difference was smaller after adjustment for distance (adjusted risk difference 1.7 fewer tests per 100 deliveries [95\% CI -2.9 to -0.6$]$ ). We found no difference in the use of antibiotics among women with a positive test result for group B streptococcus. First Nations mothers were less likely to have at least 4 antenatal visits (adjusted risk difference -3.6 [95\% CI -4.6 to $-2.6]$ ), and less likely to have had an early ultrasound (adjusted risk difference -10.2 [95\% CI -11.3 to -9.3$]$ ). First Nations mothers were less likely to undergo induction of labour after prelabour rupture of membranes ( $>12 \mathrm{~h}$ : adjusted risk difference -4.9 [95\% CI -8.9 to -0.9$]$ ) or for post-dates pregnancies (adjusted risk difference -10.6 [95\% CI -13.8 to -7.5$])$. We found no significant difference in the proportion of women whose planned cesarean occurred at or after 39 weeks' gestation.

Use of obstetric interventions differed between First Nations and non-First Nations mothers (Table 3). Most notably, First Nations mothers were less likely to undergo induction, and this dif-

Table 1: Characteristics of first-time mothers giving birth in British Columbia by First Nations status, 1999-2011

\begin{tabular}{|c|c|c|c|c|}
\hline \multirow[b]{2}{*}{ Characteristic } & \multicolumn{2}{|c|}{$\begin{array}{l}\text { First Nations mothers } \\
\qquad n=9152\end{array}$} & \multicolumn{2}{|c|}{$\begin{array}{l}\text { Non-First Nations mothers } \\
\qquad n=206841^{*}\end{array}$} \\
\hline & No. $(\%) \dagger$ & $\underset{\%}{\text { Missing, }}$ & No. $(\%) \dagger$ & $\underset{\%}{\text { Missing, }}$ \\
\hline Maternal age, yr, median (IQR) & $21.0(18.7-25.0)$ & 0.0 & $29.1(25.1-32.9)$ & 0.0 \\
\hline $\begin{array}{l}\text { Pre-pregnancy BMI, } \mathrm{kg} / \mathrm{m}^{2} \text {, } \\
\text { median (IQR) }\end{array}$ & $23.7(21.2-27.7)$ & 46.0 & $22.4(20.4-25.4)$ & 25.4 \\
\hline $\begin{array}{l}\text { Maternal weight gain, kg, } \\
\text { median (IQR) }\end{array}$ & $17.4(13.2-22.5)$ & 50.4 & $15.4(12.0-19.1)$ & 31.1 \\
\hline $\begin{array}{l}\text { Gestational age at birth, wk, } \\
\text { median (IQR) }\end{array}$ & $39.0(38.0-40.0)$ & 0.4 & $39.0(38.0-40.0)$ & 0.1 \\
\hline Preterm delivery (<37 wk) & $987(10.8)$ & - & 15718 (7.6) & - \\
\hline Post-dates ( $\geq 41$ wk) & $933(10.2)$ & - & $35484(17.2)$ & - \\
\hline Pre-existing diabetes & $28(0.3)$ & 0.0 & $857(0.4)$ & 0.0 \\
\hline Gestational diabetes & $275(3.0)$ & 0.0 & $13023(6.3)$ & 0.0 \\
\hline Pre-existing hypertension & $39(0.4)$ & 0.5 & $1405 \quad(0.7)$ & 1.3 \\
\hline Gestational hypertension & $781(8.6)$ & 0.5 & $16063 \quad(7.9)$ & 1.3 \\
\hline \multicolumn{5}{|l|}{ Distance to nearest hospital, km } \\
\hline 0 to 50 & $5134(65.7)$ & 14.6 & $149747(91.6)$ & 21.0 \\
\hline$>50$ to 100 & $1133(14.5)$ & - & 7824 (4.8) & - \\
\hline$>100$ to 150 & $806(10.3)$ & - & 3197 (2.0) & - \\
\hline$>150$ to 200 & $30 \quad(0.4)$ & - & $380(0.2)$ & - \\
\hline$>200$ & $716 \quad(9.2)$ & - & 2295 (1.4) & - \\
\hline Living in a rural area & 2725 (34.9) & 14.6 & $18040(11.0)$ & 21.0 \\
\hline
\end{tabular}


ference persisted after adjustment for maternal risk factors and distance to hospital (adjusted risk difference 5.9 fewer inductions per 100 deliveries [95\% CI -7.4 to -4.5$]$ ). First Nations mothers were also less likely to receive an epidural, but more likely to receive nitrous oxide-oxygen mixture. The only other intervention that First Nations cohort members were more likely to undergo was labour augmentation by artificial rupture of membranes. Although there was a large crude difference in the overall use of cesarean, the magnitude after adjustment was of small clinical importance (adjusted risk difference -1.8 [95\% CI -3.0 to $-0.7])$. We found no evidence of a difference in the proportion of cesarean deliveries performed for labour dystocia in the adjusted models, and only slightly fewer cesareans were performed for an indication of nonreassuring fetal monitoring. First Nations mothers were less likely to have an

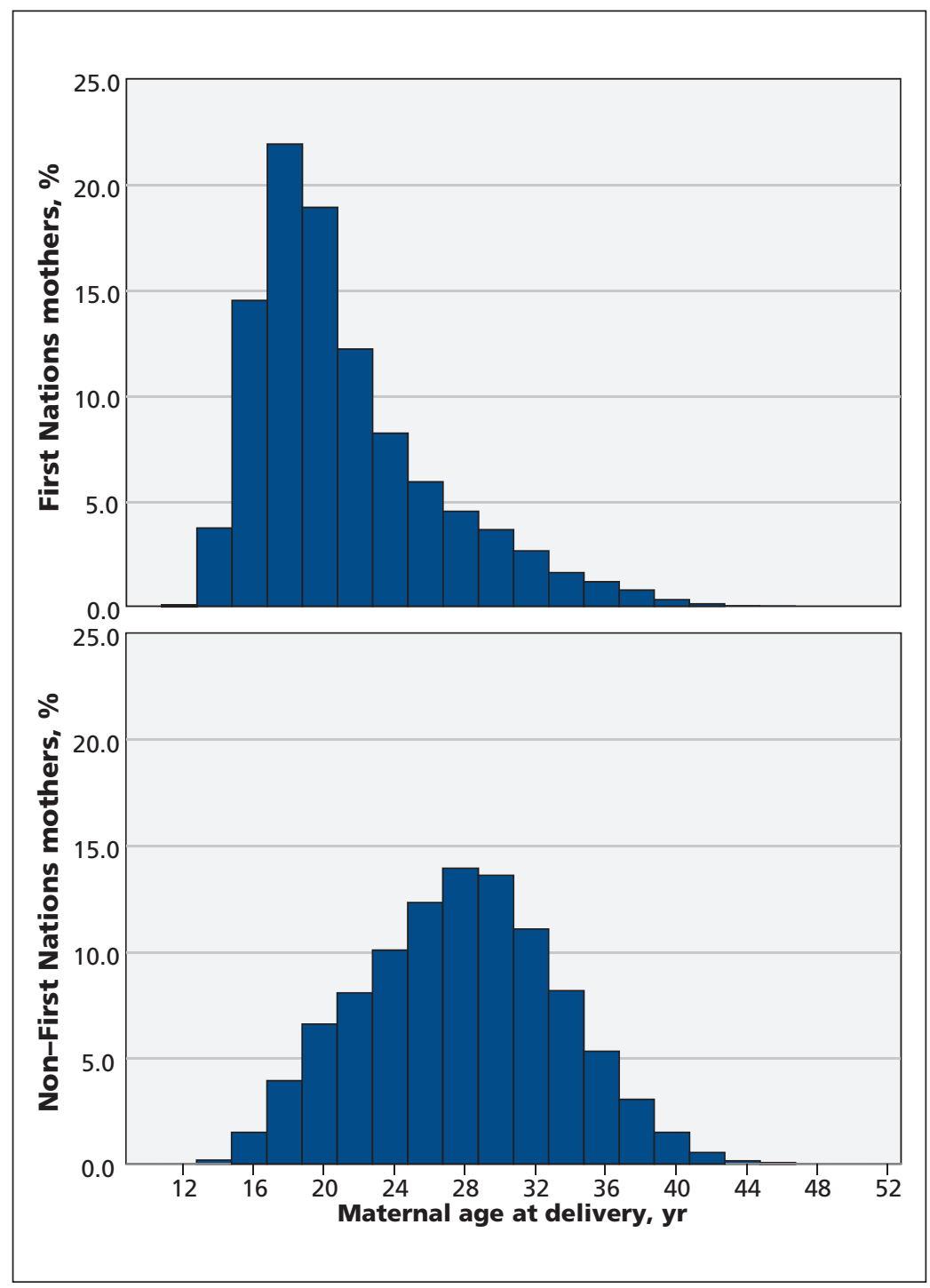

Figure 2: Maternal age at delivery among First Nations and non-First Nations first-time mothers in British Columbia. assisted vaginal delivery (forceps, adjusted risk difference -2.2 [95\% CI -2.9 to -1.5$]$; vacuum, adjusted risk difference $-1.6[95 \% \mathrm{CI}-2.4$ to $-0.9])$.

Analyses adjusting for an indicator of rurality rather than distance-to-hospital yielded consistently similar findings across all models. Analyses using complete records yielded similar results (Appendix 1).

\section{Interpretation}

We found differences in the obstetric care received by nulliparous First Nations mothers in British Columbia during the study period. First Nations mothers were less likely to have early ultrasonography, less likely to have at least 4 antenatal visits and less likely to undergo induction for indications of post-dates gestation and prelabour rupture of membranes. Because these indicators reflect current standards of care, estimated differences are not at risk for confounding by maternal risk factors, rurality or level of service at the local hospital. In addition, First Nations mothers were less likely to receive an epidural, to undergo induction of labour or to have an operative delivery, although differences in these secondary outcomes may suggest differences in maternal preferences or unmeasured factors related to their needs for these services for which we were unable to account for in our analyses.

It is possible that previously observed disparities in perinatal outcomes among First Nations women are downstream consequences of the differences we saw in provision of care. Fewer antenatal visits increase the likelihood that pregnancy complications associated with increased perinatal mortality, such as preeclampsia or intrauterine growth restriction, go undetected. Lack of early ultrasonography reduces the opportunity to detect congenital anomalies and may lead to a difference in related perinatal mortality. ${ }^{23-25}$ Early ultrasonography in the first or second trimester is the best method for estimating the delivery date and reduces inductions for post-term pregnancies. ${ }^{15}$ Randomized trials have found that labour induction for post-term gestation and for prolonged rupture of membranes decreases perinatal morbidity compared with expectant management. ${ }^{26}$ Furthermore, increased labour induction following the dissemination of randomized trial results ${ }^{27}$ was shown to coincide with a reduction in stillbirth among post-dates pregnancies in Canada. ${ }^{28}$ Ideally, we would have linked the differences found in the indicators analyzed in our study with perinatal outcomes to estimate causespecific morbidity and mortality associated with reduced care. However, because perinatal death 
is uncommon and this study involved only 9152 First Nations mothers, it was not powered to detect such differences.

The optimal rates of obstetric interventions that we studied as our secondary objective are unknown, and the appropriate use of these interventions varies according to maternal risk factors and preferences. Although signs suggest that obstetric interventions are being used too readily in developed countries, ${ }^{29-31}$ the lower rates we saw among First Nations mothers are of concern when coupled with the known increased risk of adverse perinatal and infant outcomes. However, for interventions where maternal preference partially determined service use, differences between these groups of women should not necessarily be seen as negative.

\section{Limitations}

Non-status First Nations account for $27 \%$ of the First Nations population in British Columbia, ${ }^{32}$ and these women were included in the non-First Nations cohort in this study. Although such mis- classification could lead to an attenuation of the effect estimate, the size of the bias is negligible given that non-Status First Nations constitute a small fraction of the comparator group.

We were unable to investigate how differences in care were associated with the type of health care provider, because a woman's delivery record only shows the person responsible for delivering the baby, and this person was not necessarily the same person responsible for her care during pregnancy or over the course of labour. Using the care provider on record would thus suffer from reverse causality, because obstetricians necessarily performed more cesarean deliveries and were more likely to be included on the records of women with the most difficult labours.

Some important covariables had high rates of missing data, including BMI. Body mass index is not recorded in the birth registry if information on either prepregnancy weight or height is missing, and it is unclear why the rate of missing data was higher among the First Nations cohort compared with the general population. However, our

Table 2: Proportions of women receiving standard of care services as shown by quality indicators, 1999-2011.

\begin{tabular}{|c|c|c|c|c|}
\hline Quality indicator & $\begin{array}{c}\text { Non-First Nations } \\
\text { mothers } \\
n / N(\%)\end{array}$ & $\begin{array}{l}\text { First Nations } \\
\text { mothers } \\
n / N(\%)\end{array}$ & $\begin{array}{l}\text { Risk difference } \\
\quad(95 \% \mathrm{Cl})\end{array}$ & $\begin{array}{l}\text { Adjusted }^{*} \dagger \\
\text { risk difference } \\
(95 \% \mathrm{Cl})\end{array}$ \\
\hline $\begin{array}{l}\text { GBS screening at or after } \\
\text { term }\end{array}$ & $107588 / 191123$ (56.3) & $4357 / 8165$ (53.4) & $-2.9 \quad(-4.0$ to -1.8$)$ & $-1.7 \quad(-2.9$ to -0.6$)$ \\
\hline $\begin{array}{l}\text { Use of antibiotics by } \\
\text { mothers with a } \\
\text { positive GBS test result }\end{array}$ & $22535 / 25156$ (89.6) & 934/1 049 (89.0) & $-0.5 \quad(-2.5$ to 1.4$)$ & $-0.6 \quad(-2.5$ to 1.4$)$ \\
\hline $\begin{array}{l}\text { At least } 4 \text { antenatal visits } \\
\text { in women with births in } \\
\text { the 39th week }\end{array}$ & 47 470/48 419 (98.0) & $\begin{array}{l}1990(93.9) \\
12120\end{array}$ & $-4.2 \quad(-5.2$ to -3.1$)$ & $-3.6 \quad(-4.6$ to -2.6$)$ \\
\hline $\begin{array}{l}\text { Performance of an early } \\
\text { ultrasound }\end{array}$ & $148817 / 206841$ (71.9) & $5361 / 9152$ (58.6) & $-13.4(-14.4$ to 12.3$)$ & $-10.2 \quad(-11.3$ to -9.3$)$ \\
\hline \multicolumn{5}{|l|}{$\begin{array}{l}\text { Medical induction in } \\
\text { prelabour rupture of } \\
\text { membranes at term }\end{array}$} \\
\hline$>1 \mathrm{~h}$ & 17 182/46592 (36.9) & 506/1 $564(32.4)$ & $-4.5 \quad(-6.9$ to -2.2$)$ & $-3.7 \quad(-6.1$ to -1.3$)$ \\
\hline$>12 \mathrm{~h}$ & 9 137/ 18206 (50.2) & $277 / 635$ (43.6) & $-6.6(-10.5$ to -2.6$)$ & $-4.9 \quad(-8.9$ to -0.9$)$ \\
\hline$>24 \mathrm{~h}$ & $4917 / 7336(67.0)$ & $162 / 278$ (58.3) & $-8.8(-14.6$ to -2.9$)$ & $-5.9 \quad(-11.8$ to 0.1$)$ \\
\hline \multicolumn{5}{|l|}{$\begin{array}{l}\text { Medical induction in } \\
\text { women reaching } \\
\text { post-dates }\end{array}$} \\
\hline Overall & $17681 / 35779$ (49.4) & $373 / 971$ (38.4) & $-11.0(-14.1$ to -7.9$)$ & $-10.6(-13.8$ to -7.5$)$ \\
\hline $\begin{array}{l}\text { In women with early } \\
\text { ultrasonography }\end{array}$ & $11761 / 22877$ (51.4) & $191 / 423(45.2)$ & $-6.3(-11.0$ to -1.5$)$ & $-6.3(-11.1$ to -1.4$)$ \\
\hline $\begin{array}{l}\text { In women without } \\
\text { early ultrasonography }\end{array}$ & 5 920/12902 (45.9) & $182 / 548 \quad(33.2)$ & $-12.7 \quad(-16.7$ to -8.6$)$ & $-12.1 \quad(-16.3$ to -8.0$)$ \\
\hline $\begin{array}{l}\text { Timing of planned } \\
\text { cesarean delivery for } \\
\text { breech presentation }\end{array}$ & $1929 / 4631$ (41.7) & $40 / 90(44.4)$ & $2.8 \quad(-7.6$ to 13.2$)$ & 1.04 (0.68 to 1.60$)$ \\
\hline $\begin{array}{l}\text { Note: } \mathrm{Cl}=\text { confidence inter } \\
\text { * Model adjusted for distar } \\
\text { †Missing values for distanc }\end{array}$ & $\begin{array}{l}\text { I, GBS = group B strept } \\
\text { to hospital. } \\
\text { mputed using predictiv }\end{array}$ & $\begin{array}{l}\text { ecus. } \\
\text { ean matching. }\end{array}$ & & \\
\hline
\end{tabular}


findings from the imputation models were consistent with the complete case analysis findings, implying that bias due to missing data is unlikely.

Data on socioeconomic status were unavailable, but because part of the relation between being a First Nations woman and receiving differential care may be transmitted through socioeconomic status, it is inappropriate to adjust for these factors because they capture part of the effect we were attempting to estimate. ${ }^{19-21,33}$

We calculated distance to hospital using the centre of maternal residential postal code. Misclassification introduced at each step may have led to a loss of explanatory power, resulting in residual confounding and upwardly biased estimated effects. ${ }^{34}$ Although we attempted to control for the effect of living in remote locations on outcomes using both distance to hospital and rurality of residence, it is possible that this did not adequately control for this construct. Furthermore, although we adjusted for measured maternal characteristics in the study of secondary outcomes, confounding by unmeasured characteristics may persist. Because our analysis included only nulliparous women, our findings are less relevant to the experiences of multiparous women, whose previous pregnancies may influence both the rates of the interventions we examined and the size of the differences between the groups.
Our study cannot be used to determine whether differences in provision of care were due to differences in offering interventions or in the uptake of interventions. Furthermore, we could not identify Métis and Inuit women, and the extent to which our findings are generalizable to those subpopulations is unknown.

\section{Conclusion}

We identified differences in the obstetric care received by First Nations mothers compared with the general population. Such differences warrant further investigation, given consistently found increases in perinatal mortality that may be a downstream consequence of differences in care. Future qualitative work and targeted surveys in collaboration with the First Nations Health Authority and their care providers is critical for guiding the development of new policies aimed at reducing disparities. This work should seek to understand whether differences are related to viewpoints regarding obstetric care during childbirth, differential education regarding the risks and benefits of delaying or denying interventions, differential treatment recommendations or other barriers to access. For now, obstetric care providers should ensure that all women have equal opportunity and access to services.

Table 3: Proportions of women receiving obstetric interventions during labour and delivery, 1999-2011

\begin{tabular}{|c|c|c|c|c|c|}
\hline Intervention & $\begin{array}{c}\text { Non-First Nations } \\
\text { mothers, no. }(\%) \\
n=206841\end{array}$ & $\begin{array}{l}\text { First Nations } \\
\text { mothers, no. (\%) } \\
n=9152\end{array}$ & Risk difference $(95 \% \mathrm{CI})$ & $\begin{array}{l}\text { Adjusted* risk difference } \\
\qquad(95 \% \mathrm{Cl})\end{array}$ & $\begin{array}{c}\text { Adjustedt risk difference } \\
\qquad(95 \% \mathrm{Cl})\end{array}$ \\
\hline Nitrous oxide-oxygen & $97920(47.3)$ & 4265 (46.6) & $-0.7 \quad(-1.8$ to 0.3$)$ & $-0.2 \quad(-1.4$ to 1.0$)$ & $2.1 \quad$ (0.9 to 3.4$)$ \\
\hline Epidural & $90819(43.9)$ & 3217 (35.2) & -8.8 (-9.8 to -7.8$)$ & $-5.2(-6.3$ to -4.0$)$ & $-2.8(-4.1$ to -1.6$)$ \\
\hline Labour induction $\ddagger$ & $55686(26.9)$ & 1791 (19.6) & $-7.4(-8.2$ to -6.5$)$ & $-5.9(-7.3$ to -4.5$)$ & $-5.9(-7.4$ to -4.5$)$ \\
\hline $\begin{array}{l}\text { Artificial rupture of } \\
\text { membranes }\end{array}$ & $60635(29.3)$ & 3301 (36.1) & $6.8 \quad$ (5.8 to 7.8$)$ & $(1.9,4.0)$ & $3.2 \quad(2.0$ to 4.3$)$ \\
\hline Oxytocin & $51696(25.0)$ & $1829(20.0)$ & $-5.0 \quad(-5.8$ to -4.2$)$ & $-1.1 \quad(-2.1$ to 0.0$)$ & $0.0(-1.2$ to 1.1$)$ \\
\hline \multicolumn{6}{|l|}{ Instrumental delivery } \\
\hline Forceps & $15699 \quad(7.6)$ & $297 \quad(3.2)$ & $-4.3(-4.7$ to -4.0$)$ & $-2.7(-3.3$ to -2.2$)$ & $-2.2(-2.9$ to -1.5$)$ \\
\hline \multicolumn{6}{|l|}{ Cesarean delivery } \\
\hline For labour dystocia & $22406(10.8)$ & 819 (8.9) & $-1.9(-2.5$ to -1.3$)$ & $-0.2 \quad(-0.9$ to 0.6$)$ & $-0.4(-1.2$ to 0.3$)$ \\
\hline $\begin{array}{l}\text { For nonreassuring fetal } \\
\text { monitoring }\end{array}$ & $13428 \quad(6.5)$ & $409 \quad(4.5)$ & $-2.0 \quad(-2.5$ to -1.6$)$ & $-1.0(-1.5$ to -0.4$)$ & $-0.7(-1.4$ to -0.1$)$ \\
\hline Elective & $8998 \quad(4.4)$ & $182(2.0)$ & $-2.4(-2.7$ to -2.1$)$ & -1.1 ( -1.6 to -0.6$)$ & $-1.1(-1.6$ to -0.6$)$ \\
\hline \multicolumn{6}{|c|}{$\begin{array}{l}\text { Note: } \mathrm{Cl}=\text { confidence interval. } \\
\text { *Adjusted for maternal characteristics (maternal age, prepregnancy body mass index, pre-existing or gestational hypertension, pre-existing or gestational } \\
\text { diabetes. Missing values for body mass index were imputed by use of predictive mean matching. } \\
\text { †Adjusted for distance. } \\
\text { †This model includes a statistical interaction term between age and First Nations status. }\end{array}$} \\
\hline
\end{tabular}




\section{References}

1. Smylie J, Fell D, Ohlsson A. A review of Aboriginal infant mortality rates in Canada: striking and persistent Aboriginal/nonAboriginal inequities. Can J Public Health 2010;101:143-8.

2. Auger N, Park AL, Zoungrana H, et al. Rates of stillbirth by gestational age and cause in Inuit and First Nations populations in Quebec. CMAJ 2013;185:E256-62.

3. Luo Z-C, Kierans WJ, Wilkins R, et al. Infant mortality among First Nations versus non-First Nations in British Columbia: temporal trends in rural versus urban areas, 1981-2000. Int J Epidemiol 2004;33:1252-9.

4. Richardus JH, Graafmans WC, Verloove-Vanhorick SP, et al. Differences in perinatal mortality and suboptimal care between 10 European regions: results of an international audit. BJOG 2003;110:97-105.

5. Perinatal Data Registry BC. Vancouver: Perinatal Services BC; 2013. Available: www.perinatalservicesbc.ca/health-professionals data-surveillance/perinatal-data-registry (accessed 2015 Sept. 22)

6. Discharge Abstract Database (hospital separations). Vancouver: Population Data BC; 2013. https://www.popdata.bc.ca/data/ internal/health/dad (accessed 2015 Sept. 22)

7. Frosst G, Hutcheon J, Joseph K, et al. Validating the British Columbia Perinatal Data Registry: a chart re-abstraction study. BMC Pregnancy Childbirth 2015;15:123.

8. Joseph KS, Fahey J. Validation of perinatal data in the Discharge Abstract Database of the Canadian Institute for Health Information. Chronic Dis Can 2009;29:96-100.

9. First Nations Client File. Vancouver: BC Ministry of Health; 2011. Data Extract. Data and Information Planning Committee [steward] (2011). Available: http://www.health.gov.bc.ca/data/ (accessed 2015 Sept. 22).

10. Tri-council policy statement: ethical conduct for research involving humans. Ottawa: Canadian Institutes for Health Research, Natural Sciences and Engineering Research Council of Canada, and Social Sciences and Humanities Research Council of Canada; 2014.

11. Bailit JL. Measuring the quality of inpatient obstetrical care. Obstet Gynecol Surv 2007;62:207-13.

12. Money D, Allen VM, Yudin MH, et al. The prevention of earlyonset neonatal Group B Streptococcal disease. J Obstet Gynaecol Can 2013;35:939-51.

13. Provision of effective antenatal care. Geneva: World Health Organization; 2006. Available: www.who.int/reproductivehealth/ publications/maternal perinatal health/effective_antenatal_care. pdf (accessed 2015 Jan. 18).

14. Cargill Y, Morin L, Bly S, et al. Content of a complete routine second trimester obstetrical ultrasound examination and report. $J$ Obstet Gynaecol Can 2009;31:272-5.

15. Butt K, Lim K, Bly S, et al. Determination of gestational age by ultrasound. J Obstet Gynaecol Can 2014;36:171-83.

16. Leduc D, Biringer A, Lee L, et al. Induction of labour. J Obstet Gynaecol Can 2013;35:840-60.

17. Delaney M, Roggensack A, Leduc D, et al. Guidelines for the management of pregnancy at $41+0$ to $42+0$ weeks. J Obstet Gynaecol Can 2008;30:800-23

18. Farrell S, Roye C, Crane J, et al. Statement on wait times in obstetrics and gynaecology. [published erratum in J Obstet Gynaecol Can 2008;30:311]. J Obstet Gynaecol Can 2008;30:248-70.

19. Kaufman JS, Cooper RS, McGee DL. Socioeconomic status and health in blacks and whites: the problem of residual confounding and the resiliency of race. Epidemiology 1997;8:621-8.

20. Kaufman JS, Cooper RS. Commentary: considerations for use of racial/ethnic classification in etiologic research. Am J Epidemiol 2001;154:291-8.

21. Kaufman JS. Dissecting disparities. Med Decis Making 2008; 28:9-11.

22. Rubin DB. Multiple imputation for nonresponse in surveys. New Jersey: John Wiley \& Sons; 1987.

23. Khoshnood B, De Vigan C, Vodovar V, et al. Trends in prenata diagnosis, pregnancy termination, and perinatal mortality of newborns with congenital heart disease in France, 1983-2000: a population-based evaluation. Pediatrics 2005;115:95-101.

24. Smith LK, Budd JL, Field DJ, et al. Socioeconomic inequalities in outcome of pregnancy and neonatal mortality associated with congenital anomalies: population based study. BMJ 2011;343:d4306.

25. Liu S, Joseph KS, Kramer MS, et al. Relationship of prenatal diagnosis and pregnancy termination to overall infant mortality in Canada. JAMA 2002;287:1561-7.

26. Mozurkewich E, Chilimigras J, Koepke E, et al. Indications for induction of labour: a best-evidence review. BJOG 2009; 116:626-36.

27. Hannah ME, Hannah WJ, Hellmann J, et al Induction of labour as compared with serial antenatal monitoring in post-term pregnancy. A randomized controlled trial. N Engl J Med 1992;326:1587-92.

28. Sue-A-Quan AK, Hannah ME, Cohen MM, et al. Effect of labour induction on rates of stillbirth and cesarean section in post-term pregnancies. CMAJ 1999; 160:1145-9.

29. Queenan JT. How to stop the relentless rise in cesarean deliveries. Obstet Gynecol 2011;118:199-200.

30. Main E, Morton C, Hopkins D, et al. Cesarean deliveries, outcomes, and opportunities for change in California: Toward a public agenda for maternity care safety and quality. Palo Alto (CA): Calfornia Maternal Quality Care Collaborative; 2011. Available: www.californiamidwives.org/Resources/Documents/ CMQCC-FINAL-WhitePaper March2012.pdf (accessed 2015 Jan. 18).

31. Chamberlain $\mathrm{G}$. What is the correct caesarean section rate? $\mathrm{Br} \mathrm{J}$ Obstet Gynaecol 1993;100:403-4.

32. Aboriginal peoples in Canada: First Nations people, Métis and Inuit. Ottawa: Statistics Canada; 2011. Cat. no. 99-011-X. Available: www12.statcan.gc.ca/nhs-enm/2011/as-sa/99-011-x/99-011 -x2011001-eng.cfm (accessed 2015 Jan. 18).

33. Cooper R, David R. The biological concept of race and its application to public health and epidemiology. J Health Polit Policy Law 1986;11:97-116.

34. Rothman KJ, Greenland S, Lash TL, eds. Validity in epidemiologic studies. In: Modern epidemiology. 3rd ed. Philadelphia: Lippincott Williams \& Wilkins; 2008:144.

Affiliations: Department of Epidemiology, Biostatistics, and Occupational Health (Riddell), McGill University, Montréal, Qué.; Department of Obstetrics and Gynecology (Hutcheon, Dahlgren), University of British Columbia, Vancouver, BC

Contributors: Corinne Riddell participated in the study conception and design, conducted the data analyses, interpreted the results and drafted the manuscript. Jennifer Hutcheon participated in the study conception and design, supervised the analyses, interpreted the results and revised the manuscript critically for intellectual content. Leanne Dahlgren participated in study conception and design, interpreted the findings and revised the manuscript critically for intellectual content. All authors gave final approval of the version to be published and agree to act as guarantors of the work.

Funding: This work was funded by an operating grant from the Canadian Institutes of Health Research (CIHR). Corinne Riddell received funding from CIHR in the form of a doctoral research award and was supported by a CIHR Interdisciplinary Capacity Enhanced Team Grant \#HOA-80072. Jennifer Hutcheon holds New Investigator Awards from CIHR and the Michael Smith Foundation for Health Research. Leanne Dahlgren is the Primary Investigator on the grant "Fetal and Infant Mortality and Serious Neonatal Morbidity among Status Indians in British Columbia."

Acknowledgements: The authors thank Lucy Barney and collaborators at the First Nations Health Authority and the Data and Information Planning Committee for their continuing involvement in this effort. The authors thank Kathryn Morrison, McGill University, for providing guidance on map creation using GIS software. 